\title{
Influence of Cooling Rate on Corrosion Resistance of the A383 Aluminum to Biofuels E10, E30 and E100
}

\author{
M. Santos-Beltrán ${ }^{1,2}$, A. Santos-Beltrán ${ }^{1,3}$, V. Gallegos-Orozco ${ }^{1,2}$, R. Martínez-Sánchez ${ }^{3}$, \\ C. Rodríguez-González ${ }^{2}$
}

${ }^{1}$ Universidad Tecnológica Junta de los Ríos, carretera alcama km 3 carr. chihuahua a Aldama C. P. 31313. Chihuahua, Chih. México

${ }^{2}$ Universidad Autónoma de Cd. Juárez (UACJ), Av. Del Charro No. 610 Cd. Juárez, Chih., México

${ }^{3}$ Centro de Investigación en Materiales Avanzados (CIMAV), Miguel de Cervantes No. 120, C.P.31109, Chihuahua, Chih., México

Recently, bio-fuel has been promoted worldwide as an alternative energy to fossil fuel in transport applications according to the global policy to reduce greenhouse gas emissions and consumption of crude oil. Among the bio-fuels available, bio-ethanol is an attractive candidate with the advantages of a huge resource for production, simple fabrication process and the utilization of existing techniques and facilities without the need to construct new infrastructures. Moreover, bio-ethanol blended gasoline fuels can reduce the fuel cost of automotive to approximately 1-3\% with increasing ethanol content by E10-E30 (ethanol vol.\%) compared to regular unleaded gasoline [1-4]. Attempts to increase the ethanol content from E10 to E80 or higher can impose an unpredictable non-linear corrosive effect on aluminum alloys.

Aluminum alloy A383 was melted at $740^{\circ} \mathrm{C}$ under an argon inert gas atmosphere. Three different mold were used to study the cooling rate during the casting solidification: mold steel, graphite mold sand mold. To verify the cooling rate measurements a type $\mathrm{K}$ thermocouple attached to the mold was used. Each individual solidified piece from the different molds (sand graphite and steel) were cut at $20 \mathrm{~mm}$ in diameter and $10 \mathrm{~mm}$ thick and subjected to immersion corrosion tests at room temperature and isolate from the surroundings. The medium used was a fuel mixture of commercial unleaded gasoline and anhydrous bio-ethanol with a purity of $99.9 \%$. The fuel mixture was $10,30,100 \mathrm{vol} . \%$ of ethanol content. The aluminum alloy specimen was exposed to the fuel under each ethanol content/ condition for 2000 h. Also aluminum die-cast alloy A383 samples (used in automotive parts in contact with ethanol) were prepared and subject corrosion under the same condition for comparison purposes. After the corrosion tests tests, the microstructure of the samples corroded surface was observed by scanning electron microscopy (SEM) and analyzed by energy dispersion spectroscopy (EDS).

It was found that the cooling rate during the solidification process had an important influence on the secondary dendrite arm spacing (SDAS) formation. According to the results, the corrosion is in proportion to the rate of cooling during solidification, at high cooling rate the corrosion degree is greater. The solidified sand casting mold samples showed the lowest rate of cooling, the largest SDAS and the lowest degree of corrosion. On the other hand the automotive aluminum die-cast alloy A383 sample showed small SDAS and the greater degree of corrosion. Also the biofuel corrosivity increases with the amount of ethanol, for samples with $10 \%$ vol. ethanol (E10), no corrosion was observed, for samples at 30\% vol. ethanol (E30) a small change in coloration was observed without material loss (as shown in Fig. 1), however at 100\% vol. ethanol (E100) showed regions of high corrosion. Fig. 2a and 2b, show the SEM image of the aluminum alloy A383 of the solidified sand mold sample and the automotive aluminum die-cast alloy A383 sample after the corrosion test. The Figure also shows the presence elements into the matrix. The automotive aluminum die-cast alloy A383 sample showed the higher amount of oxygen $(24.62 \mathrm{wt}$ \% O ). 
References:

[1] Charles MB, Ryan R, Ryan N, Oloruntoba R. Public policy and biofuels: the way forward?

Energy Policy 2007;35:5737-46.

[2] Yacobucci BD, Schnepf R. Selected issues related to an expansion of the renewable fuel standard (RFS). CRS report for Congress (US): Congressional Research Service; 2008. Report No.: RL34265.

[3] Hoekman SK. Biofuels in the U.S. - challenges and opportunities. Renewable Energy 2009;34:14-22.

[4] American coalition for ethanol. Fuel economy study. Sioux Falls (SD): American coalition for ethanol; 2005.

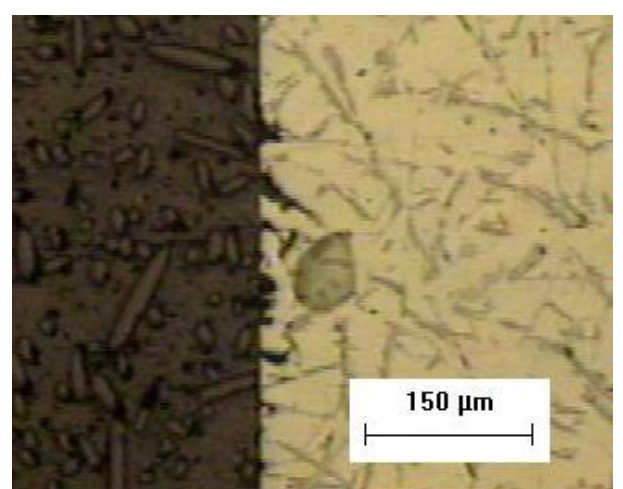

a)

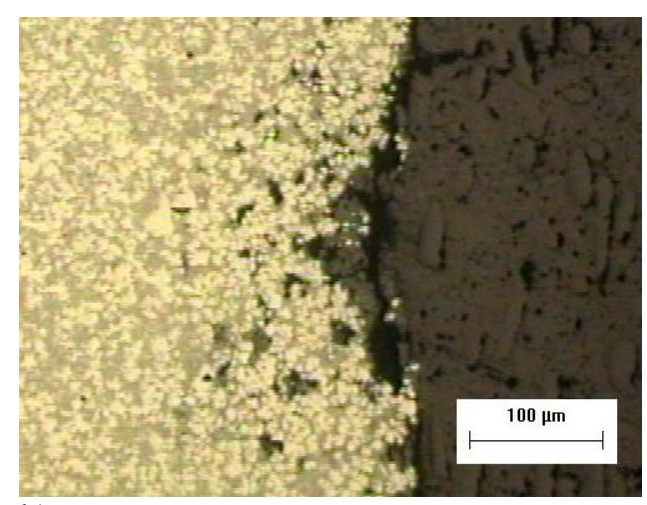

b)

Figure 1. Analysis pit depth of an optical microscope, a) sample solidified sand mold, b) the automotive aluminum die-cast alloy A383 sample.

\begin{tabular}{|l|l|l|}
\hline Element & $\boldsymbol{W t}^{\%} \%$ & $\boldsymbol{A t} \%$ \\
\hline$C K$ & 21.99 & 38.08 \\
\hline$O K$ & 09.96 & 12.95 \\
\hline AlK & 54.84 & 42.28 \\
\hline SiK & 05.07 & 03.76 \\
\hline$S K$ & 00.46 & 00.30 \\
\hline$C I K$ & 00.32 & 00.19 \\
\hline FeK & 01.31 & 00.49 \\
\hline \hline
\end{tabular}

a)

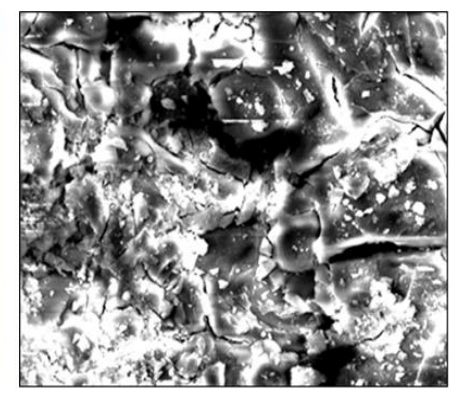

Figure 2. SEM image (1000×) and EDS analyses, a) sand mold sample and b) The automotive aluminum die-cast alloy A383 sample.

\begin{tabular}{|l|l|l|}
\hline Element & Wt\% & At\% \\
\hline$C K$ & 15.41 & 25.96 \\
\hline$O K$ & 24.62 & 31.14 \\
\hline AIK & 54.63 & 40.98 \\
\hline SiK & 00.42 & 00.30 \\
\hline FeK & 01.72 & 00.63 \\
\hline$Z n K$ & 03.19 & 00.99 \\
\hline \hline
\end{tabular}

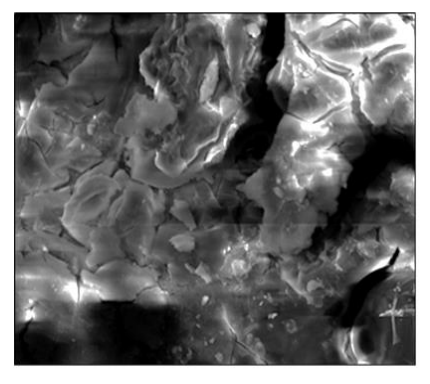

b) 